\title{
Legal Transitions: Some Welfarist Remarks
}

\begin{abstract}
MATTHEW D. ADLER*
In his remarkable 1986 article, An Economic Analysis of Legal Transitions, ${ }^{1}$ Louis Kaplow built upon earlier and pathbreaking work by Michael Graetz ${ }^{2}$ and overturned the then-conventional wisdom about legal transitions. Where the rule change itself is desirable, Kaplow argued, transition relief would generally be undesirable and indeed the fully retroactive application of the rule might be warranted. Kaplow's central points were twofold: transition relief dampened desirable ex ante incentives, for actors, to anticipate desirable legal change; and absent market failures the risk of uncompensated transitions would be optimally mitigated through insurance markets, obviating the need for governmental relief. ${ }^{3}$

Kaplow qualified his claims in various ways, ${ }^{4}$ and further qualifications have emerged in the law-and-economics literature on transitions spawned by Kaplow and Graetz (most recently Daniel Shaviro's magisterial book). ${ }^{5}$ Given failures in the insurance market, such as adverse-selection problems or administrative costs, government-provided transition insurance or even
\end{abstract}

* Professor, University of Pennsylvania Law School. Many thanks to Eric Posner, Adrian Vermeule, and the participants in the University of San Diego School of Law conference on legal transitions for their helpful comments.

1. Louis Kaplow, An Economic Analysis of Legal Transitions, 99 HARV. L. REV. 509 (1986).

2. Michael J. Graetz, Legal Transitions: The Case of Retroactivity in Income Tax Revision, 126 U. PA. L. REV. 47 (1977).

3. See Kaplow, supra note 1, at 520-66.

4. See id. at 536-50, 566-76.

5. See, e.g., Daniel Shaviro, When Rules Change: An Economic and Political Analysis of Transition Relief And Retroactivity (2000); Saul Levmore, Changes, Anticipations, and Reparations, 99 ColuM. L. ReV. 1657 (1999); Saul Levmore, The Case for Retroactive Taxation, 22 J. LEGAL STUD. 265 (1993); Kyle D. Logue, Tax Transitions, Opportunistic Retroactivity, and the Benefits of Government Precommitment, 94 Mich. L. Rev. 1129 (1996); J. Mark Ramseyer \& Minoru Nakazato, Tax Transitions and the Protection Racket: A Reply to Professors Graetz and Kaplow, 75 VA. L. REV. 1155 (1989). 
compensation might be justified. ${ }^{6}$ Given public-choice type failures in the formulation of legal rules, a transition policy of no relief or full retroactivity might slow the emergence of desirable rules. ${ }^{7}$ Even bracketing such market or governmental failures, the incentive argument for retroactivity might need to be narrowed, for example to account for legal rules that function like governmental contracts, ${ }^{8}$ or to distinguish between true "policy changes" and mere "accounting changes."

In this paper, I intend to reassess the Kaplow claim in a different wayby taking a standpoint outside law and economics but sympathetic to its most basic normative premise, namely welfarist consequentialism. One might attack the claim by adducing the nonwelfarist, nonconsequentialist "fairness" considerations that Kaplow discounted in Economic Analysis of Legal Transitions ${ }^{10}$ and has rejected more systematically in recent work with Shavell. ${ }^{11}$ I will not do that in my paper, because my own sympathies are consequentialist and, if not strictly welfarist, then close enough in the sense that I take overall well-being to be one of several genuine, foundational moral criteria $^{12}$ and, further, agree with Richard Arneson that welfare is the currency of distributive justice. ${ }^{13}$ Rather, I will assume - with the economists - that welfarism is indeed the governing moral framework for evaluating transition policy (and everything else!), and consider some foundational philosophical issues within welfarism, relevant to the transition analysis, that as far as I'm aware have been little discussed in the economics literature.

More concretely, I will imagine a welfarist social planner at some initial time $\mathrm{T}_{0}$, crafting a transition rule for some area of the law- $\mathrm{a}$ transition rule that will be applied going forward. For reasons to be mentioned in a moment, if the social planner really is welfarist in the relatively strict sense assumed to be morally appropriate by Kaplow and Shavell and by many others within normative economics, then this Planner is best seen as utilitarian. For simplicity (and because I know nothing about tax law), this concrete example will involve not tax

\footnotetext{
6. See Kaplow, supra note 1, at 536-50.

7. See, e.g., Ramseyer \& Nakazato, supra note 5.

8. See Logue, supra note 5.

9. See SHAVIRO, supra note 5, at 53-63.

10. See Kaplow, supra note 1, at 522-27, 576-81.

11. See Louis Kaplow \& SteVen Shavell, Fairness Versus Welfare (2002).

12. See Matthew D. Adler, Beyond Efficiency and Procedure: A Welfarist Theory of Regulation, 28 FLA. ST. U. L. REV. 241, 288-336 (2000). This article focused on the moral force of overall welfare, and was agnostic as between consequentialist and nonconsequentialist views incorporating an overall-welfare factor.

13. Richard J. Arneson, Welfare Should be the Currency of Justice, 30 CANADIAN
} J. PHIL. 497 (2000). 
retroactivity but the simpler case of retroactivity with respect to regulatory directives issued by an administrative agency that (I will assume) the Planner with certainty controls. By "regulatory directives," I mean directives that create legal obligations for firms or private individuals and are backed by penalties, for simplicity civil fines. Anti-pollution directives, or directives not to sell certain kinds of products, would be good examples. For simplicity, I will assume that the menu of transitionpolicy options is limited to two: simple prospectivity (a new directive is applied only to behavior occurring after the enactment of the directive) and simple retroactivity (a new directive is not only applied to postenactment behavior, but in addition individuals who previously engaged in behavior impermissible under the new directive are fined, and individuals previously fined for behavior permissible under the new directive are paid rebates for fines they incurred). Note that the Planner anticipates she will control the agency in the future, and because (by assumption) she knows herself to be utilitarian, my example is one in which otherwise-desirable transition policy ought not be rejected because it would interfere with desirable change. So this example - at least in that respect - presents a particularly strong case for retroactivity. But that case may weaken once one probes the foundations of welfarism a bit more.

\section{QUASI-WELFARISM, WEAK WELFARISM, PARETIAN WELFARISM, UTILITARIANISM}

Quasi-welfarism, weak welfarism, Paretian welfarism, and utilitarianism are increasingly restricted variants of consequentialism ${ }^{14}$ - increasingly restricted in the sense that each entry on this list is implied by the next but does not imply it. Weak welfarism is the simplest view: it say that goodness "supervenes" on welfare, that two outcomes (possible worlds) such that each person's welfare level in one outcome equals her welfare

14. By consequentialism, I mean a moral view that (1) provides a partial if not complete "goodness" ranking of possible worlds which, crucially, is evaluator-neutral; and (2) enjoins actors to perform actions that appropriately "promote" good worlds, with the conception of "promotion" fleshed out in a suitably consequentialist way, e.g., as expected goodness maximization using subjective or objective probabilities. I don't have a proposal as to what makes a "promotion" conception suitably consequentialist, and will not try to engage that issue here. On that issue, see Shelly Kagan, Normative Ethics 64-69 (1998); Richard Fumerton, ReAson And Morality: A Defense of the Egocentric Perspective 92-113 (1990); Matthew D. Adler, Risk, Death and Harm: The Normative Foundations of Risk Regulation, 87 MINN. L. REV. 1293, 1316-21 (2003). 
level in the other must be equally good. ${ }^{15}$ Paretian welfarism adds the requirement that the outcome in which at least one person's welfare is higher, and no one's is lower, must be better. To see the difference here from weak welfarism, note that a tough-minded egalitarian view that requires the "leveling down" of the welfare of the rich to increase welfare-equality is consistent with weak welfarism but not Paretian welfarism. Utilitarianism ignores distributive considerations: the goodness comparison of two worlds depends solely on the sum of welfare differences, for all affected individuals, between the two worlds. So, for example, the "prioritarian" proposal advanced by some philosophers and countenanced by many economists - that greater weight should be given to the welfare of those who are worse off-is consistent with Paretian welfarism but not utilitarianism. ${ }^{16}$ Finally, quasi-welfarism gives a central role to welfare ("central role" of course is a vague criterion) but need not respect the supervenience requirement. The quasi-welfarist might give different goodness rankings to worlds where everyone's welfare is equal as between the worlds.

Kaplow and Shavell, consistent with (what I take to be) the consensus among economists and indeed the state of the art within welfare economics, are Paretian welfarists but not utilitarians. ${ }^{17}$ Shaviro is a utilitarian. ${ }^{18}$ Which is the right approach for a welfarist? I think Shaviro's is. Weak

15. "Weak welfarism" is normally called, simply, "welfarism". See Andrew Moore \& Roger Crisp, Welfarism in Moral Theory, 74 Australasian J. Phil. 598 (1996). I have added "weak" to emphasize that a view attributing moral significance to welfare, and only welfare, need not incorporate the Pareto principle, let alone reduce to utilitarianism. The supervenience principle, as stated in the text, is too simple because it ignores the problem of incomparability. A better statement might be: One outcome cannot be better or worse than another (it must be either equally good or incomparably good) unless one person's welfare is better or worse.

16. On the difference between prioritarianism and a strict egalitarian view that would require "leveling down," see Dennis McKerlie, Equality and Priority, 6 UTILITAS 25 (1994); Derek Parfit, Equality or Priority, in THE IDEAL OF EQuAlity 81-125 (Matthew Clayton \& Andrew William eds., 2000); Larry Temkin, Equality, Priority, and the Leveling Down Objection, in The IdEAL OF EQuality 126-61 (Matthew Clayton \& Andrew William eds., 2000).

17. See Kaplow \& Shavell, supra note 11, at 15-38. As they crisply state: "Under the rubric of welfare economics, the conception of social welfare is based on individuals' well-being. Specifically, social welfare is postulated to be an increasing function of individuals' well-being and to depend on no other factors." Id. at 24. See generally ROBIN BOADWAY \& NEIL BRUCE, WELFARE ECONOMICS 139 (1984).

It has been pointed out to me that Kaplow, in other work, has adopted a utilitarian rather than Paretian welfarist framework. My characterization of Kaplow's general moral view is based on FAIRNESS AND WELFARE, his most thorough (and quite recent) defense of a general view, and not his entire scholarly corpus.

18. See SHAVIRO, supra note 5, at 16-19. 
welfarism and Paretian welfarism are unstable approaches: unstable not in the sense that they're conceptually incoherent, but in the sense that the considerations which count in their favor (as against utilitarianism) tend to push all the way to quasi-welfarism. Those considerations are, again, distributive. But, as Dworkin brilliantly argued in his work on equality, and as others have elaborated, it is deeply counterintuitive to think that distributive norms would ignore the relevant persons' responsibility for their welfare levels. ${ }^{19}$ An outcome in which $\mathrm{P}_{1}$ has a substantially lower welfare level than $\mathrm{P}_{2}$, through no fault of his own, is worse (qua fair distribution) than an outcome in which $\mathrm{P}_{1}$ 's welfare is lower than $\mathrm{P}_{2}$ 's as a result of $\mathrm{P}_{1}$ 's own imprudent decisions.

What does this mean for the analysis of transition policy? It means that we should conserve analytic resources by ignoring the less plausible moral frameworks (weak welfarism and Paretian welfarism) and focus on the more plausible ones (quasi-welfarism and utilitarianism). And if our welfarism is axiomatic, then utilitarianism follows. Nonretroactivity has, in the past, been defended with reference to distributive considerations: the "horizontal equity" argument for prospectivity might, for example, be understood as a distributive argument. ${ }^{20}$ Whatever the persuasiveness of this argument for the weak or Paretian welfarist, it will be ignored by the utilitarian.

Which is not to say that a quasi-welfarist who cares about the distribution of welfare and injects responsibility into the mix will be persuaded by the "horizontal equity" argument. That quasi-welfarist should care-I tend to think - about the fair distribution of lifetime welfare. ${ }^{21}$ Imagine that person $\mathrm{P}_{1}$ is retroactively sanctioned through no fault of his own, while $P_{2}$ is not. This difference might be counterbalanced by some gain that $P_{1}$ but not $P_{2}$ reaps in another domain, at another time. Given that possibility and the concern for lifetime, not temporally or situationally narrower equality, the best redistributive institutions might be much more synoptic than transition policy. As Kaplow puts it: "[S]eeking equality in each instance and seeking equality overall are not necessarily equivalent .... [C]onsistent pursuit of the former will often accomplish

19. See Ronald Dworkin, What is Equality? Part 2: Equality of Resources, 10 PHIL. \& PUB. AFF. 283 (1981). The literature generated by Dworkin's article is reviewed by Barbara Fried's contribution to this symposium. For a recent contribution to that literature, see CHRISTOPHER LAKE, EQUALITY AND RESPONSIBILITY (2001).

20. See, e.g., SHAVIRO, supra note 5, at 17-19.

21. See Adler, supra note 14 , at 1324-25. Cf. LARry S. Temkin, Inequality 232-44 (1993). 
the latter in an inefficient manner." 22 But even if nonretroactivity is part of the optimal legal regime given distributive considerations, i.e., within quasi-welfarism, that point is irrelevant for the utilitarian.

\section{What IS WeLFare? Preferentialist AND SubStantive ViEWS}

Utilitarianism is really a family of moral views, not a fully specified view. The utilitarian enjoins actors to promote good outcomes and equates goodness with overall well-being. But, for example, the concept of welfare can plausibly be specified in different ways, ${ }^{23}$ and these different specifications give rise to different variants of utilitarianism. A welfare view answers the following question: Under what conditions is some person $\mathrm{P}$ better off in one outcome $\mathrm{O}_{1}$ as compared to another $\mathrm{O}_{2}$ ? The set of plausible answers to that question can be divided up in a number of ways; for my purposes here, the best division is a binary division between preferentialist and substantive welfare views. Preferentialist views require that $\mathrm{P}$ prefer $\mathrm{O}_{1}$, in some sense, to be better off in that world, but do not require that $\mathrm{O}_{1}$ be objectively better for $\mathrm{P}$. Substantive views build in objective improvement as a necessary if perhaps not sufficient condition for a welfare improvement. By "objectively better" I mean something like this: $\mathrm{O}_{1}$ is objectively better for $\mathrm{P}$ than $\mathrm{O}_{2}$ iff everyone, under idealized conditions, would prefer to be $\mathrm{P}$ in $\mathrm{O}_{1}$ as opposed to being $\mathrm{P}$ in $\mathrm{O}_{2}{ }^{24}$ Here are some examples of preferentialist views:

- $\quad \mathrm{P}$ is better off in $\mathrm{O}_{1}$ than $\mathrm{O}_{2}$ iff he actually prefers $\mathrm{O}_{1}$ to $\mathrm{O}_{2}$.

- $\mathrm{P}$ is better off in $\mathrm{O}_{1}$ than $\mathrm{O}_{2}$ iff he ideally (under full information, say) prefers $\mathrm{O}_{1}$ to $\mathrm{O}_{2}$.

- $\quad \mathrm{P}$ is better off in $\mathrm{O}_{1}$ than $\mathrm{O}_{2}$ iff he actually prefers $\mathrm{O}_{1}$ to $\mathrm{O}_{2}$ and this preference is self interested (in some sense that does not appeal to objective improvement).

22. Kaplow, supra note 1, at 579-80.

23. Good overviews of the philosophical literature on well-being include: JAMES Griffin, Well-Being: Its Meaning, Measurement and Moral Importance 7-72 (1986); Derek Parfit, Reasons and Persons 493-502 (1984); T.M. Scanlon, What We Owe to Each Other 108-43 (1998); L.W. Sumner, Welfare, Happiness AND ETHICs 45-137 (1996); Mozaffar Qizilbash, The Concept of Well-Being, 14 Economics AND PHILOSOPHY 51 (1998).

24. See Adler, supra note 12, at 297-300. 
And here are some examples of substantive views:

- $P$ is better off in $\mathrm{O}_{1}$ than $\mathrm{O}_{2}$ iff $\mathrm{O}_{1}$ is an objective improvement for $\mathrm{P}$ and this improvement is grounded in some hedonic difference between the two outcomes (e.g., $\mathrm{P}$ is in sufficient pain in $\mathrm{O}_{2}$ that everyone ideally would prefer to be $\mathrm{P}$ in $\mathrm{O}_{1}$ instead).

- $P$ is better off in $\mathrm{O}_{1}$ than $\mathrm{O}_{2}$ iff $\mathrm{O}_{1}$ is an objective improvement for $\mathrm{P}$ and this difference is grounded in some "perfectionist" difference between the outcomes, i.e., $\mathrm{P}$ is better with respect to activities and characteristics essential to humans.

- $P$ is better off in $\mathrm{O}_{1}$ than $\mathrm{O}_{2}$ iff $\mathrm{O}_{1}$ is an objective improvement for $\mathrm{P}$.

- $P$ is better off in $\mathrm{O}_{1}$ than $\mathrm{O}_{2}$ iff $\mathrm{O}_{1}$ is an objective improvement for $\mathrm{P}$ and $\mathrm{P}$ prefers $\mathrm{O}_{1}$.

The distinction between preferentialist and substantive welfare views thus delineated is useful for my purposes here because the latter but not the former class of views incorporate an objectivist "screen" that helps preclude esoteric features of outcomes from counting as welfare improvements. Ironically, it will turn out, it is not preferentialism-the class of views favored by economists - but substantivism that will help Kaplow respond to an antiretroactivity argument of the following sort: "People prefer that they and others not be treated in ways that they believe to be unfair; they believe retroactivity to be unfair; by frustrating this preference, the state reduces overall welfare." I will discuss the problem that esoteric preferences pose for transition policy anon, but first let me mention some other ways in which the general utilitarian notion of maximizing overall welfare needs to be specified.

\section{WHAT IS OVERALL WELFARE? INTERPERSONAL COMPARISONS AND THE PROBLEM OF OUTCOME-INCOMPARABILITY}

Utilitarians owe us an account of interpersonal comparisons. Here's one, which on most days I tend to think is pretty plausible and which builds on Harsanyi's work: $\mathrm{O}_{1}$ is better for overall welfare than $\mathrm{O}_{2}$ iff (1) $\mathrm{O}_{1}$ is a Pareto-improvement ${ }^{25}$ over $\mathrm{O}_{2}$ or if not (2) everyone under ideal

25. I use terms like "Pareto-improvement," "Pareto-noncomparable" and so on in the welfare sense, not the preference sense. $\mathrm{O}_{1}$ is a Pareto improvement relative to $\mathrm{O}_{2}$, in 
conditions would prefer a lottery giving her an equal probability of being each person in $\mathrm{O}_{1}$, to a lottery giving her an equal probability of being each person in $\mathrm{O}_{2}{ }^{26}$ Note that this construct for interpersonal comparisons leads to incomparability in the welfare ordering of worlds. ${ }^{27}$ Economists like to assume a complete ordering over outcomes, i.e., each outcome is either better, or worse, or equally good as every other outcome. $^{28}$ But on the modified Harsanyi account just offered some outcomes will be incomparable with respect to overall welfare. And I haven't seen a plausible construct for interpersonal comparisons that avoids some incomparabilities.

Indeed, it may be the case that the scope of incomparability, with respect to the overall-welfare ranking of outcomes, is quite wide. Actual rule-drafting choices, in this world, almost always lead to Paretononcomparable outcomes. That is, for most of the sets of choices with respect to general rules that governmental actors have faced and will face in the future, it is not the case that the outcome of one choice in the choice set is a Pareto-improvement over the outcomes of all the other choices. And it may be the case that the correct account of interpersonal comparisons leaves unranked most (if not all) of these Paretononcomparable outcomes that rule-drafters actually confront. Consider my modified Harsanyi construct. The construct clearly does succeed in producing a decisive ranking over pairs of outcomes like the following:

- In $\mathrm{O}_{1}$, one person suffers a mild, recurring headache. In $\mathrm{O}_{2}$, he does not suffer the headache but thousands of other people die prematurely.

- In $\mathrm{O}_{1}$, a few ultrarich have fewer cars and houses than they would in $\mathrm{O}_{2}$. In $\mathrm{O}_{2}$, many more people fall below the poverty line than in $\mathrm{O}_{1}$.

But does the construct produce a decisive ranking of pairs of outcomes like the following?

- In $\mathrm{O}_{1}$, the regulator enacts a strict environmental safety code. In $\mathrm{O}_{2}$, he does not. In $\mathrm{O}_{1}$, many people lose their jobs or have much lower incomes, as compared to $\mathrm{O}_{2}$. But some premature deaths are avoided, and wilderness areas, enjoyed by many, are preserved.

the welfare sense, if someone is better off in $\mathrm{O}_{1}$ and no one is worse off - which doesn't entail anything about anyone's preferences except on certain (specifically, preferentialist) views of welfare.

26. See Adler, supra note 12, at 289-300.

27. See id. at 300-01.

28. See BOADWAY \& BRUCE, supra note 17, at 137-69. 
- In $\mathrm{O}_{1}$, my Planner enacts a policy of simple retroactivity. In $\mathrm{O}_{2}$, my Planner enacts a policy of simple prospectivity. In $\mathrm{O}_{1}$, some actors incur retroactive fines that they would avoid in $\mathrm{O}_{2}$; but others avoid injuries that they would suffer in $\mathrm{O}_{2}$ (given the positive incentive effects of retroactivity).

I don't know.

Assume that the transition-rule choice faced by my Planner or, more generally, by some Planner in some other context is a choice between transition rules the outcomes of which are incomparable with respect to overall welfare. What does this mean for the choice of rule? It means, to be blunt, that the choice is morally ungoverned, within utilitarianism. ${ }^{29}$ The Planner is free to pick either transition rule; the overall-welfare criterion does not guide her with respect to that choice; she is free to, say, flip a coin, just as she would be free to flip a coin in choosing between two outcomes identical for everyone's welfare. More precisely, transition-rule choices that lead to outcomes that are either incomparable or precisely equal with respect to overall welfare are choices that an omniscient utilitarian Planner is free to make either way. An omniscient Planner knows, for sure, which outcomes would result from the choices available to her. Choices by epistemically limited Planners pose additional complications: the Planner, now, sees each choice as a lottery over outcomes, such that some but maybe not all of the possible outcomes in each lottery are incomparable with some but maybe not all of the possible outcomes in the other lotteries. I cannot pursue these complications here. I'll just conjecture that, if the incomparability of resulting outcomes leaves the omniscient utilitarian transition Planner free to do whatever she wants, then epistemically limited utilitarian Planners will also in some cases gain a moral freedom that they would lack were a complete welfare ordering over outcomes to obtain.

In short, given sufficiently wide overall-welfare incomparability as between Pareto-noncomparable outcomes, most transition choices actually faced by rule-drafters may be a matter of utilitarian indifference. It may just not matter, within utilitarianism, which choices these officials make: whether they choose grandfathering, full retroactivity, or anything in between. Of course, the wide incomparability that creates this kind of moral freedom would also create moral freedom with respect to

29. See Matthew D. Adler, Incommensurability and Cost-Benefit Analysis, 146 U. PA. L. REV. 1371, 1404-08 (1998). 
substantive legal choices. It also wouldn't matter whether clean air acts are enacted, whether workplace safety regimes are put into place, whether monopolies are broken up. The problem of incomparability is a "nuclear threat" to the whole field of utilitarian policy analysis - a threat that economists (with a few exceptions, like Sen) ${ }^{30}$ have ignored. Transition policy is hardly uniquely threatened; then again, it is not exempt from the threat either.

\section{How SHOULd EPISTEMICALLY LIMITED PlanNERS CHOOSE? SPECIFYING THE “EX ANTE” VIEW}

For the remainder of these comments, I'll ignore the problem of incomparability and assume (implausibly!) that the right view of welfare, be it preferentialist or substantive, generates a methodology for interpersonal comparisons sufficiently powerful to rank all outcomes as better, worse, or equally good with respect to overall welfare.

A different problem cannot be ignored, however, one to which I have already alluded. Transition planners, like other policymakers and agents, are not omniscient. For the omnisicent utilitarian agent, faced with a range of possible actions $\left\{\mathrm{A}_{1} \ldots \mathrm{A}_{\mathrm{n}}\right\}$ at some time $\mathrm{T}$, each action is matched with its actual outcome-the actual world that would result, were the action to be chosen - and the agent simply chooses that action with the best outcome. For imperfect (nonomniscient) agents, matters are not so simple. Imperfect agents fall into two types. Some agents are epistemically limited but computationally perfect. Others are both epistemically and computationally imperfect. Herbert Simon's work on "bounded rationality" focused on the latter type. ${ }^{31}$ Standard theorizing in economics assumes the former type. ${ }^{32}$ The expected-utility maximizer is an agent who does not know the actual outcomes of his choices (he lacks full empirical information, or in other words gaining that information is costly), but has unlimited ability to represent possible outcomes and choices to himself and to determine all the logical entailments, with respect to those choices and outcomes, of whatever rationality axioms we might posit.

30. See, e.g., Amartya Sen, Choice, Welfare and Measurement 203-21 (1982); Amartya Sen, Social Choice Theory, in 3 HANDBooK of MATHEMATICAL ECONOMICs 1073, 1127-28 (Kenneth J. Arrow \& Michael D. Intriligator eds., 1986). 1997).

31. See Herbert A. Simon, Models of Bounded Rationality (3 vols. 1982-

32. See, e.g., David M. Kreps, A Course in Microeconomic Theory 71-131 (1990) (presenting expected-utility model of choice). 
I, too, will ignore the problem of computational limits and assume that my Planner is epistemically but not computationally limited. What should she do? First, are there probability numbers linking each choice with the possible outcomes of that choice? I'll assume there are. ${ }^{33}$ Second, are the numbers relevant to her choice subjective probabilities (numbers that represent the partial beliefs of some person(s), her own beliefs and/or others') or objective probabilities? ${ }^{34}$ Finally, if it is subjective not objective probabilities that bear upon the Planner's choice, do her own subjective probabilities take priority in some way? ${ }^{35}$

I believe that subjective, not objective probabilities are relevant to the Planner's choice. In other words, she should maximize subjective expected overall welfare. Each action $\mathrm{A}_{\mathrm{i}}$ facing her, from $\left\{\mathrm{A}_{1} \ldots \mathrm{A}_{\mathrm{n}}\right\}$, amounts (in her view) to a lottery over the possible outcomes $\left\{\mathrm{O}_{1} \ldots \mathrm{O}_{\mathrm{m}}\right\}$. To each outcome included in the $\left\{\mathrm{O}_{1} \ldots \mathrm{O}_{\mathrm{m}}\right\}$ lottery, she attaches a subjective probability number representing her partial belief that $A_{i}$, if chosen, would result in that outcome. Each outcome also has attached a cardinal welfare number representing the overall welfare in that outcome. (For simplicity, assume that the Planner knows with certainty what that number is.) Using these welfare numbers, plus the subjective probability numbers just described, the Planner can calculate the subjective expected overall welfare of each action and then, from $\left\{A_{1} \ldots A_{n}\right\}$, choose the action whose subjective expected overall welfare is greatest. The objectivist $^{36}$ stipulates, instead, that the probabilities used to calculate expected overall welfare are objective-where the standard proposal for achieving objectivity, here, is to construe probabilities as relative frequencies rather than degrees of belief. ${ }^{37}$ That proposal is problematic,

33. Some accounts of choice under uncertainty are nonprobabilistic - most famously the "maximin" account. See Simon French, Decision Theory: An InTROduction to the MATHEMATICS OF RATIONALITY 36 (1986).

34. See KREPS, supra note 32, at 71-131 (presenting both objective-probability and subjective-probability variants of expected-utility account).

35. On this issue, see Philippe Mongin \& Claude d'Aspremont, Utility Theory and Ethics, in 1 HANDBOOK OF UTILITY THEORY 371, 437-44 (Salvador Barbera et al. eds., 1998).

36. The subjectivism/objectivism issue, here, involves the nature of probability and is orthogonal to the substantivism/preferentialism issue discussed above-which concerns the nature of welfare.

37. On the nature of objective and subjective probabilities, see L. JONATHAN Cohen, An Introduction to the Philosophy of Induction And Probability (1989); Donald Gillies, Philosophical Theories of Probability (2000); Henry E. Kyburg, Jr., Probability and Inductive Logic (1970); Roy Weatherford, Philosophical Foundations OF PROBABILITY THEORY (1982). 
I think, for reasons I can only mention here. First, the probabilities relevant to expected utility maximization must be capable of linking actions and highly specified, nonrepeatable outcomes (whole worlds, which include the occurrence of various events at various particular times, or to particular people), but relative frequencies-which look to how frequently various outcomes occur in indefinitely repeated experiments - can at most link actions and repeatable outcomes. Second, the whole point of the expected-utility idea is to define a decisionprocedure that is sensitive to the situation of an epistemically limited agent. We might talk about what the agent ought to do in an external sense, or what she reasonably does given her internal states (specifically, her limited knowledge). "Externally," she should choose the action with the best outcome; internally, if computationally unlimited, she maximizes subjective expected overall welfare (where, in turn, the maximizing choice at a particular time might be to acquire more information). ${ }^{38}$

Turn, now, to the problem of the relative priority of the utilitarian Planner's probabilistic beliefs versus the probabilistic beliefs of others. At a given point in time $\mathrm{T}$, the epistemically limited but computationally unlimited Planner faces a set of possible actions $\left\{\mathrm{A}_{1} \ldots \mathrm{A}_{\mathrm{n}}\right\}$, a set of possible outcomes $\left\{\mathrm{O}_{1} \ldots \mathrm{O}_{\mathrm{m}}\right\}$ and her own subjective probabilities at that time linking each action and each outcome. Those probability numbers need not be the same as the subjective probability numbers that individual Citizens ascribe to the action-outcome pairs. What should the Planner do in the case of such deviation? Here's an extreme example: (1) some action $\mathrm{A}^{+}$maximizes expected overall welfare, given the Planner's subjective probabilities, but (2) some other action $\mathrm{A}^{*}$ is "ex ante efficient," in the sense that each Citizen (using his own subjective probabilities and focusing on his own welfare) calculates that the expected goodness for him of $\mathrm{A}^{*}$ is greater than the expected goodness of $\mathrm{A}^{+}$and all other choices in $\left\{\mathrm{A}_{1} \ldots \mathrm{A}_{\mathrm{n}}\right\}$.

My appeal to the epistemic situation of the Planner answers this question: the Planner should maximize subjective expected overall welfare given her own subjective probabilities, even if some other choice is ex ante efficient based on Citizen beliefs, and more generally regardless of what the Citizens believe. ${ }^{39}$ To be sure, the Planner's own beliefs are

38. It should be noted that the subjectivist about probability and expected welfare does impose epistemic rationality constraints on subjective probabilities. At a minimum, they must satisfy the probability calculus. Further, probabilities must be dynamically updated in a rational way; the individual is not free at any time to adopt a new set of absolute and conditional probabilities satisfying the calculus but wholly unrelated to his earlier set. Yet further constraints may obtain.

39. See Matthew D. Adler, The Puzzle of "Ex Ante Efficiency": Does Rational 
potentially sensitive to Citizen beliefs; for example, if she believes a Citizen to be expert in some domain, then (ceteris paribus) the Planner will revise her prior beliefs to match the Citizen's. This can be captured in a standard, Bayesian model of dynamic subjective probability revision ${ }^{40}$ : over time, the Planner learns facts that cause her to modify her beliefs, including facts about others' beliefs. But the beliefs that determine, at any particular time, what an epistemically limited utilitarian Planner should do are just hers; it is those beliefs, not the Citizens', that link together with the overall-welfare ranking of outcomes to determine what she "ought" (in an internal sense) to do.

\section{SubJECTIVE EXPECTED Welfare MAXIMIZATION AND INCENTIVES}

We are now in a position to talk, a little more concretely, about the Planner's choice at $T_{0}$ between a transition rule of prospectivity (any changes in regulatory directives in the domain will be applied prospectively) and retroactivity (any changes will be applied retroactively, both to sanction actions previously permissible but now impermissible, and to refund sanctions on actions now permissible but earlier impermissible). If the Planner maximizes subjective expected overall welfare, which transition rule ought she to choose?

Here's one way to think about the question. At $T_{0}$, a particular set of substantive rules for the regulatory domain is in place (call this set $\mathrm{R}_{0}$ ). The Planner anticipates that, at some later time $T_{1}$, she may modify the substantive rules, in light of events between $T_{0}$ and $T_{1}$. By events, $I$ mean changes in the population, in physical characteristics of Citizens, in their physical location, in their social structure, changes in the external world, new information about physical or social facts, and so on, which are relevant to the Planner and relatively epistemically accessible to the Planner - anything that might occur, thereby change the Planner's beliefs about the upshots of various possible directives, and thus prompt her to modify the substantive set of rules $\mathrm{R}_{0}$. For simplicity, assume that, when a relevant event occurs, the Planner learns that for sure. ${ }^{41}$ This allows us to conceptualize the changes in the Planner's

Approvability have Moral Weight?, 151 U. PA. L. REV. 1255 (2003).

40. See, e.g., JaCk HirShleifER \& John G. Riley, The ANALytics of UnCERTAinty AND INFORMATION 167-208 (1992); KYBURG, supra note 37, at 68-76; RiCHARD C. JEFFREY, THE LOGIC OF DECISION 164-83 (2nd ed. 1983).

41. This is too simple, of course, but the problem I'm about to delineate would also surely arise under a more complex model. 
beliefs, and resultant changes in the substantive rules, as a simple process of Bayesian updating. ${ }^{42}$ At $\mathrm{T}_{0}$, the Planner has "prior" (absolute) probabilities for all manner of propositions, and conditional probabilities for all manner of propositions, conditional on various events that might occur between $T_{0}$ and $T_{1}$. Between $T_{0}$ and $T_{1}$, some concatenation of events occurs; the Planner learns that, and updates her "prior" probabilities using the conditional probabilities she had at $\mathrm{T}_{0}$. This results in a new, "posterior" set of probability ascriptions at $T_{1}$. The Planner at $T_{1}$ then chooses the new rule, $\mathrm{R}_{1}{ }^{\mathrm{P}}$, that maximizes subjective expected overall welfare given her new, "posterior" probabilities.

This picture of event-occurrence and belief-change between $T_{0}$ and $T_{1}$ feeds back into the Planner's choice of transition rule at $\mathrm{T}_{0}$. The Planner at $\mathrm{T}_{0}$ (who after all is computationally unlimited) can represent to herself all possible concatenations of events that might occur between $\mathrm{T}_{0}$ and $\mathrm{T}_{1}$, and to which she would have epistemic access. For each concatenation, the Planner at $T_{0}$ can calculate: (1) the rule $\mathrm{R}_{1}{ }^{\mathrm{P}}$ she would enact at $\mathrm{T}_{1} ;$; the optimal pattern of behaviors between $T_{0}$ and $T_{1}$; (3) the various behavioral patterns that might occur if the Planner adopts a transition rule of simple prospectivity; (4) the various behavioral patterns that might occur if the Planner adopts a transition rule of simple retroactivity. For each concatenation, in short, there is an expected cost to a transition rule of prospectivity (the behavioral deviation under that rule from the optimal pattern), but also an expected cost to a transition rule of retroactivity (the behavioral deviation under that rule from the optimal pattern). Aggregating probabilistically over concatenations, using her probabilities at $\mathrm{T}_{0}$, the Planner chooses the transition rule that maximizes subjective expected overall welfare.

What this picture suggests is that the Planner, at the time she chooses the transition rule, might expect there to be "incentive costs"-deviations from the optimal (by her lights) pattern of citizen behaviors - under both retroactivity and prospectivity regimes. Note that this can occur even if, for a given concatenation of events, the optimal pattern of behaviors in the preamendment period ${ }^{43}$ involves full compliance with the new substantive rule $\mathrm{R}_{1}{ }^{\mathrm{P}}$ that the Planner expects to enact (given that concatenation) at the end of period, at $\mathrm{T}_{1}$. Why? Assume the transition rule is a retroactivity rule. Then, for a given concatenation of events during the preamendment period, each individual Citizen will try to predict what the new rule $R_{1}{ }^{\mathrm{P}}$ will be, and will try to comply with that rule. ${ }^{44}$ But these predictions might be incorrect. More precisely: for

\footnotetext{
42. See sources cited supra note 40.

43. By this I mean the period after $\mathrm{T}_{0}$ and prior to $\mathrm{T}_{1}$.

44. This again is a simplifying assumption. Whether a given Citizen will try to
} 
each possible concatenation of events that might arise during the preamendment period, the Planner at $\mathrm{T}_{0}$ has beliefs about (1) what rule she would enact at $T_{1}\left(R_{1}{ }^{\mathrm{P}}\right)$, and (2) what any given Citizen would predict $\mathrm{R}_{1}{ }^{\mathrm{P}}$ to be $\left(\mathrm{R}_{1}{ }^{\mathrm{C}}\right)$. Nothing requires that these hypothesized rules coincide. The Planner might well believe that a given concatenation will lead her to maximize subjective expected overall welfare down the road by enacting $R^{*}$, but also believe that this concatenation will lead various Citizens to predict that she will maximize subjective expected overall welfare down the road by enacting $\mathrm{R}^{+}$(and therefore that those Citizens, in a retroactivity regime, will try to comply with $\mathrm{R}^{+}$). This deviation between the rule the Planner expects to enact in a given scenario, and the rule she expects to be expected to enact, might (among other things) lead the Planner to conclude that prospectivity provides better incentives than retroactivity.

Perhaps a yet more concrete example would help. The Planner regulates foods and drugs, by keeping a list of prohibited products and attaching civil fines to the use or distribution of these products. For any given product, she determines whether it would maximize subjective expected overall welfare to prohibit or permit the product, roughly by balancing the expected health and/or hedonic benefits to the population of Citizens who would use the product if permitted, against the expected health and/or hedonic costs. At $\mathrm{T}_{0}$, she enacts the initial list $\mathrm{L}_{0}$. For a given possible concatenation of subsequent events (changes in the population, new information about the health effects of various products, etc.), the Planner expects to change the list to $L_{1}{ }^{P}$ at $T_{1}$. If she puts in place a prospectivity rule at $\mathrm{T}_{0}$, then (she predicts) firms will continue to

comply with his prediction of $\mathrm{R}_{1}{ }^{\mathrm{P}}$ during the preamendment period, assuming a transition rule of retroactivity, depends upon the probabilities that his violation will be detected and that $\mathrm{R}_{1}{ }^{\mathrm{P}}$ will be retroactively enforced in his case, the predicted sanction if that occurs, and the expected benefit of noncompliance. For simplicity, I'm assuming that the probabilities of detection and enforcement-the Citizen's subjective probabilities - and the size of the sanction are large enough to induce compliance in all cases. Indeed, talk of a single $\mathrm{R}_{1}{ }^{\mathrm{P}}$ that each Citizen predicts the Planner to adopt is oversimplified; really, if the Citizens are fully rational, each has a conditional subjective probability distribution over possible rules the Planner might adopt, conditional on each possible concatenation of events during the preamendment period, and maximizes his expected utility given this distribution plus his probability distributions over detection, enforcement, and the stringency of the sanction as well as the benefits of noncompliance. My general point - that the Planner might predict deviations from the optimal pattern of behaviors to occur under both sorts of transition regimes - in no way hinges on these simplifying assumptions. 
sell and consumers will continue to use products permissible under $\mathrm{L}_{0}$ but not $\mathrm{L}_{1}{ }^{\mathrm{P}}$ during the preamendment period, and firms will decline to sell and consumers will decline to use products impermissible under $\mathrm{L}_{0}$ but permissible under $\mathrm{L}_{1}{ }^{\mathrm{P}}$. That will be costly, by her lights. On the other hand, if she puts in place a retroactivity rule and the particular concatenation of events under consideration occurs, then (she envisions) (1) a given Citizen, using his own probabilities, will determine that the expected-overall-welfare-maximizing list is $\mathrm{L}_{1}{ }^{\mathrm{C}} ;$; (2) the Citizen will predict that the Planner will change the list to $\mathrm{L}_{1}{ }^{\mathrm{C}} ; 4$ (3) expecting retroactivity, the Citizen will comply with $\mathrm{L}_{1}{ }^{\mathrm{C}}$, which may differ from $\mathrm{L}_{1}{ }^{\mathrm{P}}$. That, too, may be costly. The expected cost will depend on the predicted deviation between the list the Planner would adopt, $\mathrm{L}_{1}{ }^{\mathrm{P}}$ and the list she expects the Citizen to predict her to adopt, $\mathrm{L}_{1}{ }^{\mathrm{C}}$.

This deviation might readily arise if the Citizen is an irrational consumer - if he doesn't process information in a rational way (at a minimum, in conformity with the probability calculus). The very predicate for governmental regulation of foods, drugs, and other such products is that consumers, in part because of epistemic irrationality, fail to reach judgments that (by the government's lights) maximize their own welfare. A fortiori, irrational consumers might fail to reach judgments about the maximization of overall welfare that match the Planner's judgments. But the problem I'm trying to describe is much broader than that of irrationality. Rational Citizens might disagree about the welfaremaximizing response to different events. (Formally, this arises because their priors are different. $)^{46}$ Perhaps this is not a possibility where the

45. To make this concrete story most tractable, I have assumed that (the Planner believes that) the Citizen's first-order beliefs about what list maximizes welfare for a given concatenation, and the Citizen's second-order beliefs about what list the Planner believes maximizes welfare for a given concatenation, are the same. Note that the two need not be the same. In other words, the Citizen might believe the Planner to have different views about welfare-maximization than his own-for example, because of the difference between their political party affiliations. In general, it is the Planner's beliefs about each Citizen's second-order beliefs, not about each Citizen's first-order beliefs, that are relevant to the Planner's prediction of citizen behavior during the preamendment period and, therewith, her choice of transition policy.

46. It should be stressed that the subjectivist model of probability allows individuals to have radically different probability assignments, and generally entails convergence only on the assumption that individuals are presented with large amounts of identical information sufficient to "overwhelm" divergent priors. See RogER M. COOKE, EXPerts in Uncertainty: Opinion and Subjective Probability in Science 110-12 (1991); Michael D. Resnik, Choices: AN InTROduCtion to DeCision TheORY 55-56 (1987). Stronger assumptions about convergence are standard within various branches of economics. For example, game theorists commonly abide by the so-called "Harsanyi doctrine": "All players begin the game with the same beliefs about the probabilities of 
relevant probabilities are objective, but it certainly is a possibility where the relevant probabilities are subjective. At $T_{0}$, the Planner and each rational Citizen has prior subjective probabilities, quite possibly different in important respects, over various propositions. Events occur during the preamendment period, and based on these, plus their priors, the Planner and each Citizen determine what the welfare-maximizing amendment to the rule would be. There might be quite a range, here - a range evidenced by the heated policy debates on all manner of issues among researchers, policy analysts, and others whose disagreements persist despite a shared consequentialism and welfarism. Therefore - and this is the crucial point for my purposes - there might also be a substantial difference at the initial stage of transition-rule choice $\left(\mathrm{T}_{0}\right)$ between what the Planner expects to enact in response to certain events, and what the Planner predicts various rational Citizens to expect her to enact in response to those events. And that can cut against the enactment of a retroactivity rule. ${ }^{47}$

the moves Nature will make." ERIC RASMUSEN, GAMES AND INFORMATION: AN InTRODUCTION to GAME TheORy 50 (2nd ed. 1994). And the "rational expectations" approach in economics, which figures importantly within Shaviro's treatment of transition policy, traditionally presupposes the following: "Agents' subjective probability distributions coincide with the objective probability distribution of events." DEBORAH A. REDMAN, A READER's Guide to RATIONAL EXPECTATIONS: A SuRVEy AND COMPREHENSIVE ANNOTATED BiBliogRAPHY 8 (1992). Such assumptions, however useful for the tractability of formal models, should not blind us to the possibility of divergent priors and the implications of that possibility for our policy choices, for example our choice of transition policy. See Mongin \& d'Aspremont, supra note 35, at 440 n.95 ("For modeling purposes, economists often assume that prior probabilities are equal. It is important to realize that this 'common prior assumption' is introduced for methodological reasons and does not have any choice-theoretic foundation.").

47. In this particular case, I have assumed, the Planner believes there to be an identity between the Citizen's first-order beliefs about welfare-maximization and the Citizen's second-order beliefs about the Planner's beliefs about welfare-maximization. See supra note 45 . Therefore what drives the deviation between the rule that the Planner expects to enact, and the rule the Planner expects to be expected to enact, is the firstorder disagreement about welfare maximization. It might be argued that, once the identity assumption is relaxed, the problem I have described disappears - since firstorder disagreement about welfare-maximization is, in principle, consistent with secondorder convergence about what the Planner believes to maximize welfare. (In a society split into many ideological factions, everyone might know exactly what the ideology of the longstanding monarch is.) But one cannot insist on second-order convergence a priori. The Planner might have been recently appointed, or have made no effort to publicize her views, or have done so but without success given citizen apathy, or have done so but without success given her affiliation with a party that (like every other party in the relevant society) has tried to mimic the views of the median voter, or . . . . 
To sum up: on a subjective expected welfare view, the utilitarian Planner's choice of transition rule is dependent, in a complicated way, on her higher-order as well as first-order beliefs: specifically, as I have presented things, on her third-order beliefs as to what Citizens would believe that she would believe to be welfare-maximizing, which need not coincide with her first-order beliefs about welfare-maximization. On this view of things, it seems hard to make general statements about the desirability, qua incentives, of retroactivity versus prospectivity. It bears emphasizing that the problem I'm describing is orthogonal to the policy change/accounting change distinction (as I understand it) ${ }^{48}$ Contemplating some possible concatenation of events during the preamendment period, and some new rule $\mathrm{R}_{1}{ }^{\mathrm{P}}$ that she would adopt in response to those events, the Planner might believe that anticipatory preamendment compliance with $R_{1}{ }^{P}$ would be better than continued preamendment compliance with

$\mathrm{R}_{0} \cdot \mathrm{R}_{1}{ }^{\mathrm{P}}$, then, would be a policy change and not a mere accounting change. But the Planner might also believe that a retroactivity rule would induce preamendment compliance by a given Citizen with $\mathrm{R}_{1}{ }^{\mathrm{C}}$ not $\mathrm{R}_{1}{ }^{\mathrm{P}}$ (where $\mathrm{R}_{1}{ }^{\mathrm{C}}$ is the new rule that, the Planner believes, the Citizen expects the events to induce the Planner to adopt). If the Planner believes this sort of deviation to be sufficiently large and widespread, she might decide that prospectivity not retroactivity is the welfare-maximizing option even in the case of a true policy change.

\section{SUBJECTIVE EXPECTED WELFARE MAXIMIZATION AND INSURANCE}

One of the interesting features of the subjective expected welfare view is its agnosticism about the benefits of markets and other choicefacilitating mechanisms - even on a preferentialist view of welfare. For any given choice by a Citizen, there is a potential wedge between the goodness of that choice from the Citizen's perspective and the goodness from the Planner's perspective created by the potential difference in their subjective probability assessments. If there's a product that the Citizen believes has a high probability of satisfying his preference for a certain taste sensation, and a low probability of frustrating his preference for bodily integrity, the Citizen rationally consumes it. If the Planner ascribes a sufficiently lower probability to the outcome in which the food produces the desired taste sensation, or a sufficiently higher probability to the outcome in which the food kills or injures the Citizen, then (bracketing the welfare of other persons, or a Citizen preference for autonomy), the Planner maximizes subjective expected overall welfare

48. See SHAVIRO, supra note 5, at 53-63. 
by banning the Citizen from buying the product. ${ }^{49}$

This agnosticism about markets and individual choice carries over to insurance markets. In some possible outcome, the Citizen's wealth position is low (say, because he has been fined a large amount for a legal infraction). If the Citizen is rational and risk-averse and self-interested, and if he ascribes a sufficiently high probability to the outcome, then he will contract with a risk-neutral insurance firm to insure against the outcome even though there is some administrative cost to the contract which he and/or the firm bear. If there are no externalities, then this contract is ex ante efficient relative to the choice of not contracting. But-from the Planner's perspective- the contracting choice might not maximize subjective expected overall welfare. If the Planner ascribes a lower probability to the insured-against outcome than the Citizen, and if the administrative costs of the insurance contract are large enough, then (from the Planner's perspective) the expected overall welfare benefit of the contract will not justify the expected overall welfare cost. Reciprocally, it might be ex ante efficient for a citizen to decline to insure against (what he takes to be) a low-probability outcome, but overallwelfare-maximizing from the Planner's perspective for the insurance to be provided.

The upshot: there is no a priori reason for the Planner to be sanguine about the insurance transactions that a retroactivity rule would trigger. ${ }^{50}$ Imagine that the Planner is choosing between three variants of the retroactivity rule: (1) retroactivity with no provision governing insurance; (2) retroactivity with a prohibition on any insurance to cover retroactive civil sanctions; (3) retroactivity with mandatory (partial) government insurance to cover retroactive civil sanctions. Insofar as the Planner expects Citizens to overestimate or underestimate (by the Planner's own lights) the possibility of various rule changes, she will have reason to choose the second or third rule, or something like these, rather than the first.

49. See Adler, supra note 39, at 1276-79.

50. Kaplow states that "[p]erhaps the strongest case for some government response to risk is presented by situations in which certain actors underestimate the likelihood of loss and thus refuse to purchase insurance when it is in their interest to do so." Kaplow, supra note 1 , at 549. This suggests an objectivist account of risk and epistemically irrational or limited agents whose estimates of the objective risk are mistaken. By contrast, my picture is one of (possibly) fully rational agents - the Planner and Citizens-whose subjective probability assessments diverge as these may do, such that insurance market transactions which are welfare maximizing from some agents' perspectives are not welfare maximizing from others'. 


\section{The (Potential) Welfare RELEVANCE OF ESOTERIC FACTS}

The Planner is choosing at $\mathrm{T}_{0}$ between various transition rules, in my example simple retroactivity and simple prospectivity. Which choice maximizes the Planner's subjective expected overall welfare depends on two things: (1) her probability distribution over possible outcomes, conditional on each choice; and (2) her valuation of the outcomes, i.e., the level of overall welfare in each outcome. In my discussion of incentives and insurance, I focused on the first determinant of the Planner's choice. But we also need to look at the second. Imagine a universe in which only certain hedonic states are intrinsic constituents of welfare-absent differences in these states, outcomes are identical for overall welfare. Imagine, now, a universe in which a much wider range of things can change the welfare status of outcomes: interpersonal relationships, accomplishments, mental states that are not hedonically charged, deviations from personal or social norms, and so forth. It would be extraordinary if retroactivity rules were appropriate in just the same legal contexts, in the first universe, as in the second.

A simple preferentialist view of welfare remains standard among economists. ${ }^{51}$ This view says: $\mathrm{O}_{1}$ is better for $\mathrm{P}$ than $\mathrm{O}_{2}$ iff $\mathrm{P}$ prefers $\mathrm{O}_{1}$ to $\mathrm{O}_{2}$ (with further provisos for cases where P's preferences vary temporally or modally). But P can prefer anything. A preference is a kind of "proattitude": a choice-relevant mental state directed onto some proposition or fact. There is nothing, in the sheer concept of a preference, to restrict the kinds of facts onto which preferences are directed. ${ }^{52}$ In short, the simple preference-based view of welfare permits the widest possible range of things to count as intrinsic welfare constituents.

This is a real threat to the utilitarian case for retroactivity. The following sorts of facts are inevitable upshots of the Planner's choice of the retroactivity rule or, if not, she will presumably ascribe these sorts of facts a higher probability than if the prospectivity rule is chosen. If the facts are intrinsically dispreferred, by one or more Citizens, then (on the simple preferentialist view) this reduces the expected overall welfare benefit of choosing retroactivity.

Dispreferrable Esoteric Consequences of Retroactivity

- Retroactive sanctions (potentially dispreferred as a kind of treatment that the Citizen believes to be unfair; note that

51. See Daniel M. Hausman \& Michael S. McPherson, Economic Analysis AND MORAL PHILOSOPHY 71-83 (1996).

52. See Adler, supra note 12 , at 262-64. 
the Citizen might prefer not just that he not be treated this way, but that others too not be treated this way).

- "Horizontal inequity" (the difference in treatment between those who complied with the old rule but were sanctioned retroactively for breaching the eventual new rule, and those who complied with both rules, potentially dispreferred insofar as the Citizen believes this difference to be inequitable).

- Being at risk of a retroactive sanction (What I have in mind, here, is not the ordinary way in which the subjective probability of a retroactive sanction influences the choices of a rational Citizen who disprefers an outcome in which he is sanctioned, but rather the more unusual case of a preference against the risk of a sanction taken as a feature of outcomes - a ceteris paribus preference on the Citizen's part against a possible world in which there is a high probability, at some time, that he will be retroactively sanctioned later on). ${ }^{53}$

- Anxiety about future retroactive sanctions (the negative affective states that occur in some Citizens worried about whether their now-legal conduct will be retroactively sanctioned).

- Ex post demoralization (the frustration and anger that occur in some Citizens after their conduct is sanctioned retroactively).

- Ex post outrage (the frustration and anger that occur in some Citizens after others are sanctioned retroactively, which the Citizens perceive to be unfair or inequitable).

Within a simple-preferentialist view of welfare (1) the existence of preferences over these sorts of facts is a contingent matter (nothing in principle precludes their existence) and (2) the strength of preferences over these sorts of facts is a contingent matter (nothing in principle precludes preferences against perceived unfair treatment, perceived

53. Persons can intrinsically disprefer the risk of adverse occurrences-disprefer that risk, taken as a feature of outcomes-just as they can intrinsically disprefer such occurrences themselves. Consider an ordinary Joe who prefers that he not die, also prefers that he not fear death, and finally prefers that he not be the victim of a game of Russian Roulette (even a game that doesn't kill him and that causes him no fear because he's unaware of it). See Adler, supra note 14, at 1351-52. 
horizontal inequity, the risk of being sanctioned, and so on from being very strong). And indeed it seems empirically plausible that people do have fairly strong intrinsic preferences against retroactivity insofar as they believe it to be unfair or inequitable.

To put the point another way: the nonconsequentialist or nonwelfarist moral arguments against retroactivity that the welfarist counts as misplaced can reenter the picture in the guise of morally grounded preferences against retroactivity. And at this point the welfarist who is also a simple preferentialist about welfare must give ground. Simple preferentialism, because of its catholicism about welfare, requires the transition Planner to include these preferences as well as preferences against sanction risk, anxiety, demoralization, outrage and other esoteric consequences of retroactivity in the welfare calculus. ${ }^{54}$

What about substantive welfare theories? Look first at the following exemplary lists of substantive values proposed by leading welfare theorists:

Griffin: Accomplishment, autonomy, understanding, enjoyment, deep personal relations. ${ }^{55}$

Finnis: Life, knowledge, play, aesthetic experience, sociability, practical reasonableness, religion. ${ }^{56}$

Parfit: Moral goodness, rational activity, the development of one's abilities, having children and being a good parent, knowledge, the awareness of true beauty. ${ }^{57}$

Nussbaum: Life, bodily health, bodily integrity, use of the senses, imagination and thought, the emotions, practical reason, affiliation, interaction with other species, play, control over one's environment. ${ }^{58}$

Even under Nussbaum's quite expansive list, it's hard to see how perceived unfairness or inequity, in the third-person or even first-person sense- the treatment of others in a way that the Citizen takes to be unfair or inequitable, or his own treatment in a way that he takes to be unfair or inequitable - counts as a welfare setback. If this treatment gives rise to certain emotional states, e.g., demoralization or outrage, then by virtue of Nussbaum's list (and Griffin's, if not Parfit's or

54. Kaplow would, I take it, happily concede this point about the welfare relevance of morally motivated preferences, which is discussed at length in a different context in his work with Shavell. See KAPLOW \& SHAVELL, supra note 11, at 21-23, 77-78, 431-36.

55. James Griffin, Value Judgement: Improving our Ethical Beliefs 29-30 (1996).

56. John FinNis, NATURAL LAW AND NATURAL Rights 59-99 (1980).

57. DEREK PARFIT, REASONS AND PERSONS 499 (1984).

58. Symposium on Martha Nussbaum's Political Philosophy, 111 ETHICs 5 (2000). 
Finnis') it will be welfare-reducing. But morally dispreferred treatments are not, without more, substantive welfare setbacks. At most one might say that certain kinds of governmental actions, if generally thought to be morally wrong, might - even absent attendant emotional states - reduce the strength of the political "community" and thereby harm affiliational goods. But this would presumably require the relevant beliefs to be fairly widespread. As for the putative harm in risk itself: I have argued at length elsewhere that risk is not a substantive harm, in the sense of being a welfare-reducing feature of outcomes. ${ }^{59}$ Risk is, of course, relevant to any actor's choice, within an expected-utility account of choice; but given two worlds differentiated by the fact that in one some Citizen is at risk of sanction or an even graver setback such as serious bodily injury or death, while in another he does not face that risk, the two worlds are (without more) substantively just the same for the Citizen's welfare.

Is the welfare economist, then, put to the choice of either abandoning the preferentialism so central to economics, or conceding that the case for retroactivity within any legal domain is wholly contingent on the preferences against the esoteric consequences of retroactivity not being too strong? In other words, can some of the esoteric consequences of retroactivity be drained of welfare force within the preferentialist family of theories? Perhaps. One might try to appeal to full information ${ }^{60}$ : no one, under full information, would care about living in a world where (with less information) she believes unfair treatment or inequity to occur. This seems like a strong claim. I do find plausible (and indeed implicitly said as much above) that some idealized agents would not disprefer being a person who perceives unfairness or inequity to occur in the world, with respect to others or herself, absent attendant emotional states on that person's part. ${ }^{61}$ But the stronger claim that no idealized agent could have such a preference may be too strong. Ditto for the claim that no idealized agent would disprefer being at risk, absent

59. See Adler, supra note 14. My argument, specifically, is that (1) risk in the objective or relative-frequency sense is not a substantive welfare setback; and that (2) risk in the subjective sense is a substantive welfare setback as a component of fear, and perhaps as a kind of ignorance (where someone ascribes a high subjective probability to some occurrence that will not, in fact, take place), but not otherwise.

60. See, e.g., David Sobel, Full Information Accounts of Well-Being, 104 ETHICS 784 (1994).

61. I implicitly said this by claiming that perceived unfairness or inequity is not an objective welfare setback absent attendant emotional states, since welfare objectivity in turn (I suggested earlier) involves a convergence in the preferences of idealized agents. 
attendant emotional states. What about appealing to self-interest? This might do a lot: insofar as the Citizen prefers that inequity or unfairness not occur to others, this seems to be an other-regarding rather than selfregarding preference. The trouble, though, is providing an account of a "self-interested" preference that does not end up making the theory substantive. No one has yet done that in a coherent and plausible way. ${ }^{62}$

\section{CONCLUSION}

To conclude these remarks: Welfarist analysis of transition policy is, most plausibly, utilitarian analysis. The utilitarian analyst needs to worry about some issues not fully mooted within the economics literature on transitions. Incomparability, here as elsewhere, is a threat to the practical significance of overall welfare. Where there are both welfare losers and welfare gainers from the choice of transition policy, as there always are, it may often not matter (qua overall welfare) which choice is made. Bracketing this point, the analyst needs to worry about the complication that preferences regarding the esoteric consequences of a retroactivity policy pose for the analysis. This issue is most readily handled by invoking a substantive not preferentialist account of welfare. But even on a substantive view the case for retroactivity seems quite contingent. That case hinges, crucially, on the incentive effects on future behavior of a previously announced policy of retroactivity. The problem, here, is that what a governmental official believes to be a desirable rule change (on some contingency) and what she believes others will believe her to see as a desirable rule change (on that contingency) can diverge. This is true, presumably, across all areas of law, and regardless of whether accurate anticipatory adjustment to the desirable new rule would be desirable. In other words, the now-standard incentive argument for retroactivity is less robust than its proponents suggest. The argument presupposes that citizens and governmental officials have sufficiently convergent beliefs about what officials would do in alternative possible futures, and such convergence is empirically contingent even if all the citizens and officials are fully rational.

62. See David Sobel, Well-Being as the Object of Moral Consideration, 14 ECoN. \& PHIL. 249, 266-69 (1998). 